\title{
Artificial rainfall technique based on the aircraft seeding of liquid carbon dioxide near Miyake and Mikura Islands, Tokyo, Japan
}

\author{
Taichi MAKI*,***,†,†, Osamu MORITA**, Yoshinori SUZUKI***, \\ and Kenji WAKIMIZU**** \\ $\left(\begin{array}{c}* \text { Faculty of Life and Environmental Sciences, Institute of Agricultural and Forest Engineering, University of } \\ \text { Tsukuba, 1-1-1 Tennodai, Tsukuba, Ibaraki, 305-8572, Japan } \\ * * \text { Office for a Sustainable Future, Fukuoka University, 8-19-1 Nanakuma, Minamiku, Fukuoka, 814-0180, Japan } \\ * * * \text { Professor Emeritus, Kyushu University, 6-10-1 Hakozaki, Higashiku, Fukuoka, 812-8581, Japan } \\ * * * * \text { Faculty of Agriculture, Kyushu University, 6-10-1 Hakozaki, Higashiku, Fukuoka, 812-8581, Japan }\end{array}\right)$
}

\begin{abstract}
This experiment of artificial rainfall was carried out by an aircraft seeding operation of liquid carbon dioxide on Feb. 26-27, 2012, near Miyake Island of the Izu Islands in Tokyo, Japan. The development of convective clouds was significant after 0.5 to $1 \mathrm{~h}$ of the seeding near Miyake Island and reached to the heights of $3000 \mathrm{~m}$ and $4000 \mathrm{~m}$ on Feb. 26 and 27, respectively. Artificial clouds appeared and rain was recognized by eye around Mikura Island on Feb. 27 as a direct effect, and it was presumed that the amount of rain increased on the mountainous area. It was clearly successful that the artificial cloud echoes were recognized about $1.5 \mathrm{~h}$ later after the seeding on Feb. 27 as a chain-type cloud echo at east-northeast of Mikura Island on the composition radar echo of Japan Meteorological Agency as an indirect effect. The echo height reached from $3000 \mathrm{~m}$ to $5000 \mathrm{~m}$ when the artificial cloud moved to the leeward side of Miyake Island. It was recognized that the seeding rate of liquid carbon dioxide with about $5 \mathrm{~g} / \mathrm{s}$ is suitable in a little inside convective cloud with an air temperature below $-5^{\circ} \mathrm{C}$.
\end{abstract}

Key words: Aircraft seeding, Artificial rainfall, Convective cloud, Liquid carbon dioxide, Miyake and Mikura Islands.

\section{Introduction}

The demand for water continues to increase as the population increases. Even in regions where the water supply has been adequate, the demand may outpace the supply. So, it has been predicted that the 21st century will suffer a water crisis. This is an especially urgent problem in countries that have arid land or desert areas. Droughts and other water-related problems are increasing in frequency as an instance of abnormal weather

Received; March 1, 2013.

Accepted; May 2, 2013.

${ }^{\dagger}$ Corresponding Author: maki@affrc.go.jp, maki.taichi.fe @u.tsukuba.ac.jp

${ }^{\dagger \dagger}$ Present affiliation: Special Senior Researcher, Japan International Research Center for Agricultural Sciences, 1-1 Ohwashi, Tsukuba, Ibaraki, 305-8686, Japan due to global warming. Thus, water deficits and difficulties obtaining water are already extant or expected to occur around the world. New and effective techniques for producing artificial rainfall are being sought to alleviate the world's water needs. It is hoped that an effective method will also protect against desertification and green arid deserts (Maki et al., 2008).

There are several existing methods for producing rainfall. There is the seeding of dry ice, seeding of silver iodide, and the scattering of liquids such as pure water, salt water and so on. However, these methods present a small amount of water, there are economic problems for these methods, and the seeding of silver iodide creates environmental problem. An artificial rainfall technique of liquid carbon dioxide (LCD) was invented by Fukuta (1988a, b), and it was proven successful at Fukuoka on Feb. 2, 1999 as the first effective rainfall production method. Several rainfall 
investigations confirmed the LCD method's property and efficiency on Feb. 2 and Oct. 27, 1999 (Fukuta et al., 2000; Wakimizu et al., 2002), the principle data of LCD seeding (Nagata et al., 2005; Nishiyama et al., 2005; Ota et al., 2005), Feb. 4 and Nov. 7, 2006, Jan. 8 and 17, 2007, Jan. 24, 2009, and other experiment results included (Maki et al., 2008; 2012). These are mainly actual experimental results on LCD seeding, except secondary indirect and topographic effects.

In the present study, the LCD technique was used in experiments operated on Miyake Island $\left(34^{\circ} 7.4^{\prime} \mathrm{N}\right.$ $\left.139^{\circ} 31.3^{\prime} \mathrm{E}\right)$ and Mikura Island $\left(33^{\circ} 52.5^{\prime} \mathrm{N}\right.$ $\left.139^{\circ} 36.1^{\prime} \mathrm{E}\right)$ of the Izu Islands of Tokyo in Japan. These islands are south of Japan's capital, and they have very small populations at a suitable period in which the experiments were conducted particularly during the cold season in winter. The main objectives in this paper are that direct and indirect effects of the LCD seeding are made clear in particular of topographical effect.

\section{Materials and Methods}

\subsection{Principles of the LCD rainfall technique}

The LCD technique developed by Fukuta (1988a, b) is as follows. LCD seeding is done by aircraft in an air layer in which the temperature is below zero and a little inside a cloud at its bottom. The LCD at $-90^{\circ} \mathrm{C}$ changes instantaneously to ice crystals $\left(10^{13}\right.$ or ten trillion particles per $1 \mathrm{~g} \mathrm{CO}_{2}$ ) (Fukuta, 1988a, b; Fu- kuta et al., 2000). These ice crystals connect with the ambient air vapor, forming snow or rain particles and thus producing snow or rain.

1) Crystal development (RETHIT effect): Air masses that have ice crystals rise due to condensation heat, enlarge by the rounding of ice crystal thermal of twin cylinder type inside a cloud, and go up to the top of the cloud.

2) Crystal dropping and expansion (FILAS effect): Super cooling clouds with ice crystals enlarge vertically and horizontally when the ice crystals go up to the top of a cloud.

The vertical up-wind gradually increases due to both the natural up-wind in the cloud and an artificial upwind created by latent heat from the ice crystals. This causes the cloud to develop further as high-humidity air masses come up under the cloud. Then, large snow or rain droplets appear in the sky and fall to the ground as snow or rain.

The cloud's development is improved when a stable air layer exists at the cloud's upper layer, because the developed cloud will be stopped at that layer and enlarge more easily in all three dimensions as horizontal moving and, in particular, vertical moving outside of the convective cloud by cooling (FILAS effect). Ice crystals produced by LCD grow actively during 0.5 to $1 \mathrm{~h}$ after the seeding. The artificial rainfall that they cause continues for several hours.

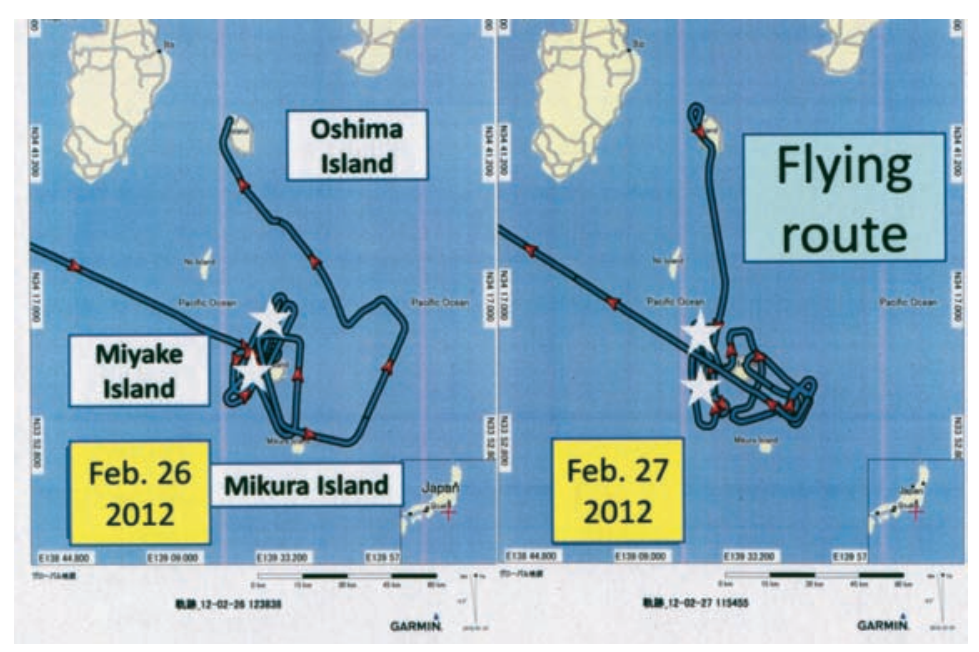

Fig. 1. Flight routes during a seeding time of liquid carbon dioxide on the seeding level of upper north-west area of Miyake Island on Feb. 26 and level of upper west area about 5 km from Miyake Island on Feb. 27, 2012 and rough seeding positions as white stars. 


\subsection{Experimental Methods}

The aircraft used was a Beechcraft of Diamond Air Service, INC. The flying routes are shown in Fig. 1.

The aircraft was flown from Nagoya Airport to Miyake Island on Feb. 26 and LCD was seeded in the sky at the west side of Miyake and stopped at Oshima Airport. After flying from Oshima to Miyake on Feb. 27, LCD was seeded at about $5 \mathrm{~km}$ from the west Miyake shore and flew back to Nagoya. The wind speed, wind direction, air temperature, and aircraft speed were monitored by the instruments, and the flying route and position of the aircraft were monitored by the computer with GPS.

The LCD was seeded from a nozzle on the bottom of the aircraft at the rate of 5-6 g/s. We flew the aircraft around Miyake and Mikura Island for $1 \mathrm{~h}$ to evaluate the effects of the seeding, observed the rain phenomena, and took photos. The data obtained were surface and upper level meteorological data and radar and satellite data issued by the Japan Meteorological Agency (JMA). These data were analyzed as well as the movement and development of the clouds affected by the LCD seeding at each time, position, and elevation.

\section{Results and Discussion}

\subsection{Meteorological Data}

Surface weather maps on the seeding dates are shown in Figure 2. A winter-type pressure pattern of west high $=$ east low type was prevalent. The radar observed high clouds due to a cold air outbreak around the Tokai and Kanto areas on Feb. 26. These clouds were mixed stratiform clouds with a structure of a convective cloud (Cumulus and Stratocumulus). However, there were no high clouds with rain around Miyake and Mikura on Feb. 27. A continental anticyclone was changing to a travelling anticyclone and moving slowly. The winter-type pressure pattern was loosened slightly. There were mixed stratiform and convective clouds produced by the cold air outbreak, but there were no developed convective clouds around the experiment area.

\subsection{Seeding of LCD near Miyake Island}

The position, elevation, and seeding times of the LCD and the meteorological data are presented below.

On Feb. 26, the seeding position was shown as white stars in the left of Fig.1 and was the sky northwest of Miyake. The seeding height was $6000 \mathrm{ft}(1829 \mathrm{~m})$.
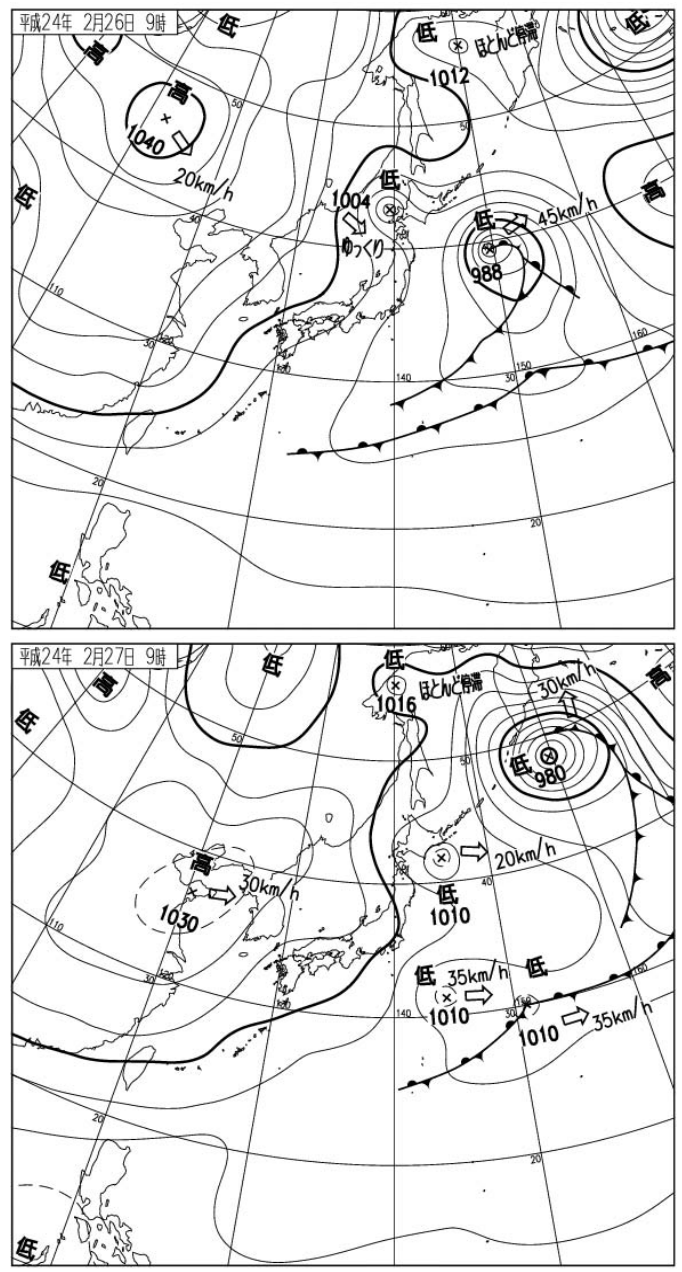

Fig. 2. Surface weather maps at 09:00 JST Feb. 26 and 27, 2012 (Japan Meteorological Agency, JMA).

The wind direction was $\mathrm{W}$, the wind speed 21kt (10.8 $\mathrm{m} / \mathrm{s}$ ), and the air temperature $-3.0^{\circ} \mathrm{C}$. There were three cloud layers, The top of the second layer was $9300 \mathrm{ft}$ $(2835 \mathrm{~m}),-8.0^{\circ} \mathrm{C}$; the bottom of the second layer was $7500 \mathrm{ft}(2286 \mathrm{~m})$. The top of the third layer was not observed, but the bottom of the third layer was $3100 \mathrm{ft}$ $(945 \mathrm{~m}), 3.5^{\circ} \mathrm{C}$. So, the thickness of the lower two layers, including separated cloud, was roughly $6200 \mathrm{ft}$ (1890 m).

The seeding direction was from SSW to ENE during the LCD seeding, and the flying speed was $153 \mathrm{kt}$ (283 $\mathrm{km} / \mathrm{h}$ ). The wind direction and speed were $\mathrm{WNW}$ and $22 \mathrm{kt}(11.32 \mathrm{~m} / \mathrm{s})$ respectively at the high layer of $9000 \mathrm{ft}(2743 \mathrm{~m})$. The seeding times were about 2, 2, and 4 minutes. 
Seeding 1: time; 11:13:42-11:15:20 JST, position; $34^{\circ} 05.20^{\prime} \mathrm{N}, 139^{\circ} 27.74^{\prime} \mathrm{E}$

Seeding 2: time; 11:19:42-11:21:35 JST, position; $34^{\circ} 05.83^{\prime} \mathrm{N}, 139^{\circ} 27.91^{\prime} \mathrm{E}$

Seeding 3: time; 11:27:09-11:31:09 JST, position; $34^{\circ} 05.72^{\prime} \mathrm{N}, 139^{\circ} 27.89^{\prime} \mathrm{E}$

On Feb. 27, the seeding position was shown as white stars in the right of Fig. 1 and was about $5 \mathrm{~km}$ west of Miyake. LCD was seeded from south to north with a seeding speed of $164 \mathrm{kt}(304 \mathrm{~km} / \mathrm{s})$. The seeding height near the bottom of a main cloud layer was 7000 $\mathrm{ft}(2134 \mathrm{~m})$ for the first seeding and $7500 \mathrm{ft}(2286 \mathrm{~m})$ for the next three seedings. The cloud bottom was 6000 $\mathrm{ft}(1829 \mathrm{~m})$ and the cloud top was $9700 \mathrm{ft}(2957 \mathrm{~m})$ making the cloud thickness $3700 \mathrm{ft}(1128 \mathrm{~m})$. There were two layers of cloud. One was main cloud and the other was a separate and sparse cloud under the main cloud at about $1000 \mathrm{~m}$. The thickness of the two layers, including separated cloud, was about $2000 \mathrm{~m}$. The wind direction was SW and the wind speed was $16 \mathrm{kt}$ (8.2 $\mathrm{m} / \mathrm{s}$ ) at 2134-2286 m (mean $2100 \mathrm{~m}$ ), and the air temperature was $-4.0^{\circ} \mathrm{C}$ at $2134 \mathrm{~m}$ and $-5.5^{\circ} \mathrm{C}$ at $2286 \mathrm{~m}$. The wind direction and speed were $\mathrm{W}$ and $17 \mathrm{kt}$ (8.7 $\mathrm{m} / \mathrm{s})$ at $10,000 \mathrm{ft}(3048 \mathrm{~m})$ and $\mathrm{WNW}$ and $36 \mathrm{kt}(18.5$ $\mathrm{m} / \mathrm{s})$ at $12,000 \mathrm{ft}(3658 \mathrm{~m})$, respectively. The seeding times were about 2, 3, 2, and 2 min.

Seeding 1: time; 09:58:23-10:00:39 JST, position; $33^{\circ} 59.94^{\prime} \mathrm{N}, 139^{\circ} 25.15^{\prime} \mathrm{E}$

Seeding 2: time; 10:06:10-10:09:00 JST, position; $34^{\circ} 03.26^{\prime} \mathrm{N}, 139^{\circ} 24.82^{\prime} \mathrm{E}$

Seeding 3: time; 10:15:06-10:17:06 JST, position; $34^{\circ} 03.17^{\prime} \mathrm{N}, 139^{\circ} 24.79^{\prime} \mathrm{E}$

Seeding 4: time; 10:24:45-10:26:46 JST, position; $34^{\circ} 11.17^{\prime} \mathrm{N}, 139^{\circ} 32.75^{\prime} \mathrm{E}$

\subsection{Experimental results and discussion on Feb. 26}

The vertical air temperature profile on Feb. 26 is shown in Fig.3 There was no inversion layer near Miyake. The thickness of an object cloud was $1890 \mathrm{~m}$, and it was initially thought that this cloud could be used as a reasonable thickness. However, the cloud's density was not adequate, so it was not suitable for LCD seeding. The cloud's development was not initially significant, but 30-40 minutes later, the cloud height had reached 2900-3000 m making it a potentially suitable cloud.

The effects of LCD seeding for Miyake on Feb. 26 are described as follows.

There were no lower clouds near Miyake, but 20 km
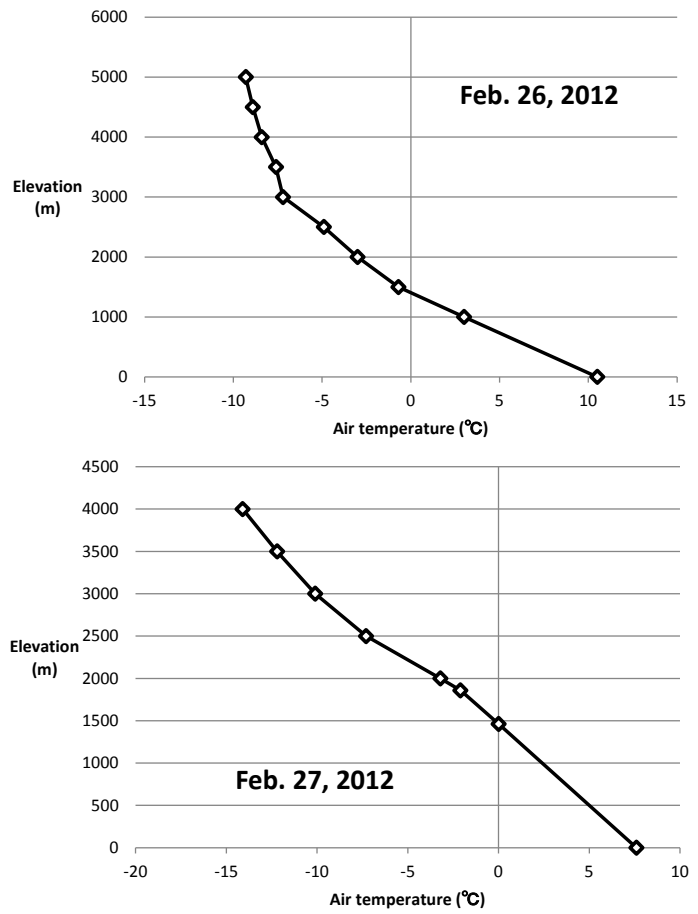

Fig. 3. Vertical profiles of air temperature above Miyake Island on Feb. 26 and Feb. 27, 2012.

from Miyake over the Mikura site, we found an artificial convective cloud by eye. We presume that the cloud produced artificial rainfall caused by the LCD seeding. The development of convective clouds was significant 0.5 to $1 \mathrm{~h}$ after the seeding at the easterly leeward side of Miyake Island and reached to the height of $3000 \mathrm{~m}$. The artificial development of clouds by the aircraft seeding of LCD was successful.

Regarding the surface weather, wind was at ENE, $3.0 \mathrm{~m} / \mathrm{s}$ at 11:00 JST; NE, $3.6 \mathrm{~m} / \mathrm{s}$ at 12:00 JST; and $\mathrm{NE}, 2.9 \mathrm{~m} / \mathrm{s}$ at 13:00 JST. Wind speed was low for this period. The wind direction at the seeding elevation was $\mathrm{W}$, and then the seeding cloud moved east $0.5 \mathrm{~h}$ later. There was presumed rainfall under the cloud over the Mikura site, and the virga, i.e., air mass with rain under the cloud, was moved to Mikura by a NNE wind at 1000-1500 $\mathrm{m}$ and NNE and NE winds at 0-1000 m (wind speed $8-10 \mathrm{~m} / \mathrm{s}$ at 9:00 JST at Hachijo Island $\left(33^{\circ} 7.3^{\prime} \mathrm{N} 139^{\circ} 46.7^{\prime} \mathrm{E}\right)$ ). It was presumed that the artificial convective cloud moved to Mikura and rainfall occurred on Mikura. Clouds were scarce over Mikura before the LCD seeding, but a cloud developed after the seeding, presumably as an artificially stimu- 
lated cloud.

Artificial clouds were observed by eye on the mountainous part of Mikura. It was thought that the origin of rain was as follows.

Artificial clouds were observed at a longer distance more than the length of Miyake from north to south. Because the wind direction was $\mathrm{W}$ at $1800 \mathrm{~m}$ and WNW at the top of the clouds, the clouds moved in an easterly direction and artificial clouds appeared in 0.5 $\mathrm{h}$ after the seeding. It was presumed that the rain fell under the cloud, the virga was moved to Mikura by a rather reverse-direction wind of NE-ENE (0-1400 m, NNE-NE at 9:00 JST at Hachijo), and that the rainfall could be observed at Mikura during the active reaction period about $1 \mathrm{~h}$ after the seeding.

There was a strong wind shear at the lower layer. It is usual that a radar echo is moved with the wind direction at the plane of $700 \mathrm{hPa}$, however the property of radar echo moved at the speed of $4.5 \mathrm{~m} / \mathrm{s}$ and the NW direction was close to that of the plane of $850 \mathrm{hPa}$ on Feb. 26. There was no radar echo for the area at 11:10 JST before seeding, but convective clouds were observed from 12:00 JST to 14:00 JST. Clouds could develop near the SW area of Mikura, but it would not be affected by a direct artificial cloud based on the vertical profiles of the air temperature and vapor in spite of the necessary discussion.

\subsection{Experiment results and discussion on Feb. 27}

The inversion layer was found at Oshima on Feb. 27, not around Miyake (Fig. 3). The LCD was seeded 4 times (Fig. 1, Fig. 4(1)).

\subsubsection{Effect of the LCD seeding at Miyake for Miyake and Mikura on Feb. 27}

On Feb. 27, the seeded cloud moved in an ENE direction after the seeding and the artificial cloud appeared. A photo of the cloud over Miyake at an early time is shown in Fig. 4(1). Photos shown in Fig. 4(2) and 4(3) are convective clouds inside and outside. A photo at about $1 \mathrm{~h}$ later shown in Fig. 4(4) presents natural clouds and artificially developed clouds with rain. A cloud developed quickly, the development of convective clouds was significant after 0.5 to $1 \mathrm{~h}$ of the seeding at the easterly leeward side of Miyake Island and an artificial cloud reached to the heights of $3500 \mathrm{~m}$ and $4000 \mathrm{~m}$ at $0.5 \mathrm{~h}$ and $1 \mathrm{~h}$ after the seeding, respectively. The development of clouds was successfully done artificially by the aircraft seeding of LCD. However it could not be detected by the radar of JMA be-

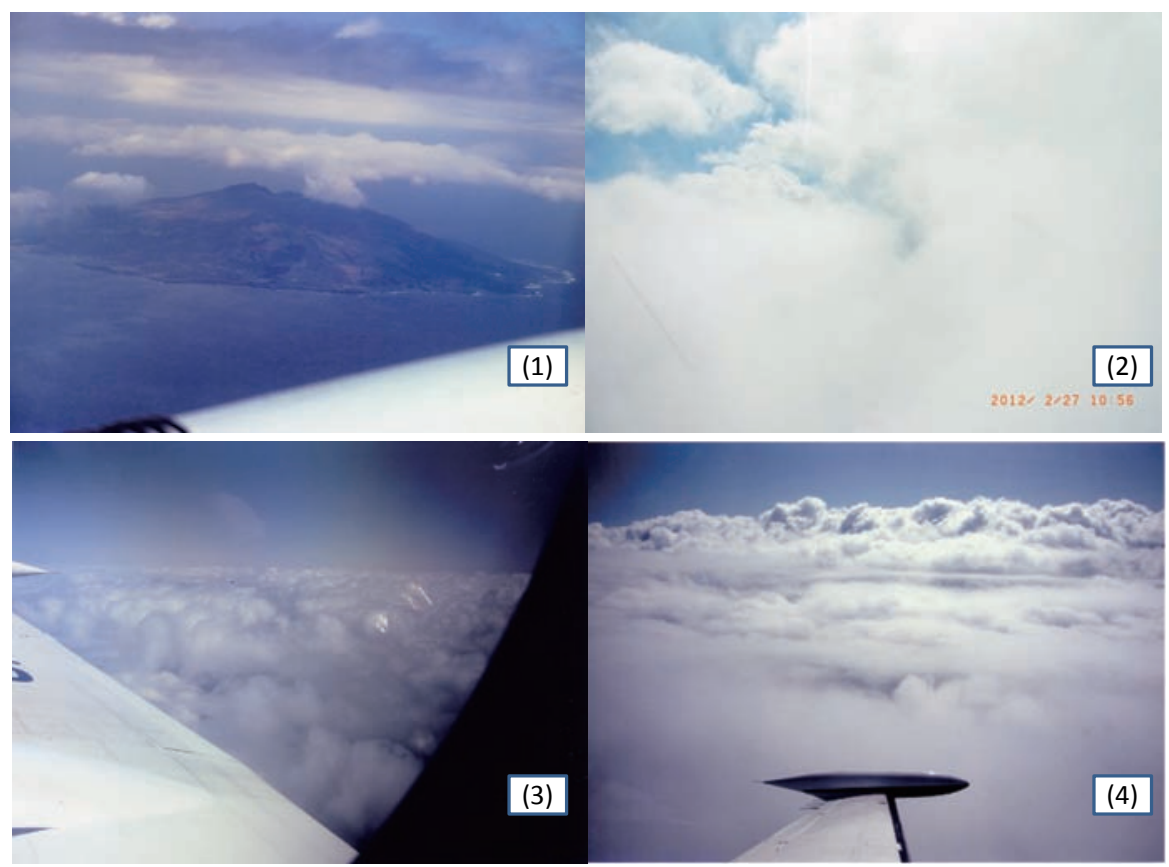

Fig. 4. Pictures of (1); over view of developing cloud on Miyake Island just after seeding, (2); inside view of developing cloud, (3); over view of more developing cloud, and (4); over view of developed cloud $0.5-1 \mathrm{~h}$ after seeding on Feb. 27, 2012. 
cause the cloud was under the height of $2000 \mathrm{~m}$, and the artificial cloud over the height of $2000 \mathrm{~m}$ was in too small an area and had too low a density.

The artificial cloud moved further, and it was raining under the cloud recognized by eye. A virga was also found at a lower layer under the seeded cloud. The virga reached Mikura about $1 \mathrm{~h}$ after the seeding, moved by a NNE-NE wind around $1500 \mathrm{~m}$. We could observe the cloud by eye, and the aircraft flew through and over the cloud as shown in the photos (Figs. 4(2), (3)). The pilot shouted suddenly "it's rain" when the rain hit on the front window. These convective clouds recognized by eye during flight were evaluated by the wind direction and wind speed concerned to the heights of the clouds and virga. The position of seeded clouds was estimated by the moving speed and direction of the clouds, shape of the clouds and the developing rate, and the following technique of the pilot.

It was presumed to be raining on the island, however, it was cloudy and there was no rain at the Mikura Village Office located at the south of the island and there were no meteorological data by JMA at Mikura. The Village Office is at a low elevation and on the leeward side of the island. The presence of rain was found in the mountainous area of island, but no rain in the surrounding lowland area was significant with differences of mountain shape, elevation, and cloud forest. The rainfall in the mountainous part of Mikura can be significant, whereas the lowland of the island does not get much rain by topography and weather condition. When one of the authors visited Mikura on June 18-20, 2011, the author also experienced the significant difference of rain at the mountain and lowland areas.

Fig. 5 shows the satellite image of visible ray. However artificial clouds of narrow seeding trajectory was not clear by the reasons of precise resolution on satellite images of visible or infrared rays, and of the shade of upper clouds.

The virga was moved ENE by SW-SSW winds for $0.5 \mathrm{~h}$, and the high humidity air mass rose up and developed into a higher cloud by the upwind based on the topography of Mikura (Fig. 6). Artificial clouds developed by seeding of LCD and developed more by the topographic effect of Mikura (Fig. 7). The relationship between the cloud formation and topography is important as physical phenomena. This relationship is explained here after.

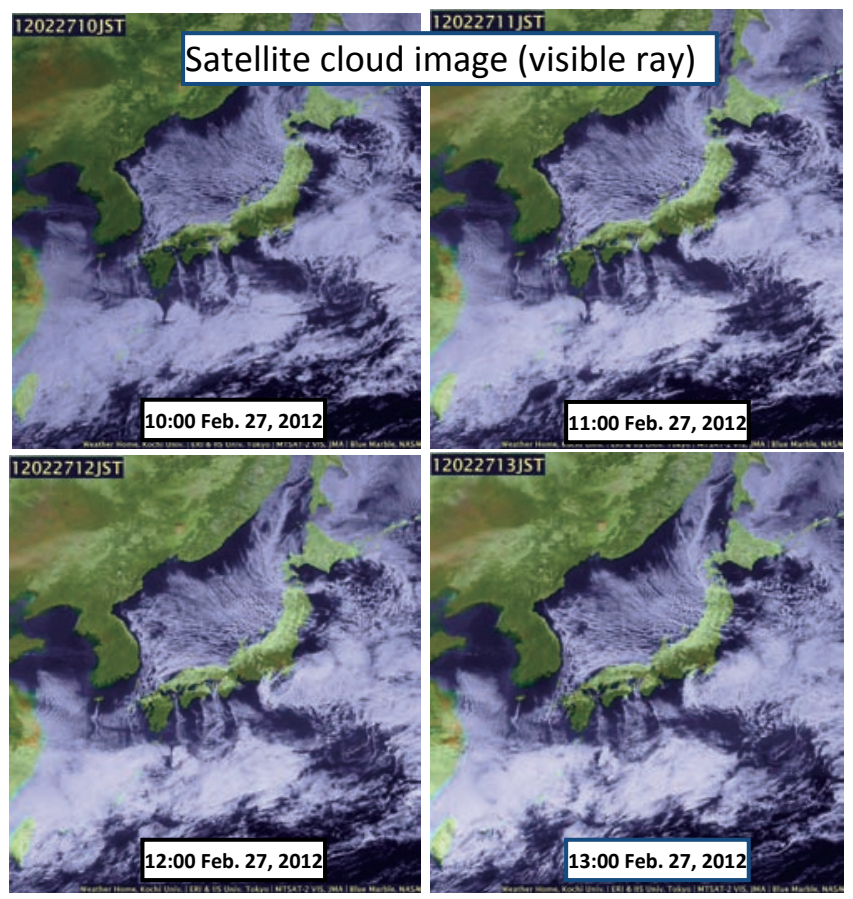

Fig. 5. Satellite cloud images around Miyake Island, Mikura and Hachijo Islands at 10:00 JST, 11:00 JST, 12:00 JST and 13:00 JST, 2012 (JMA). 


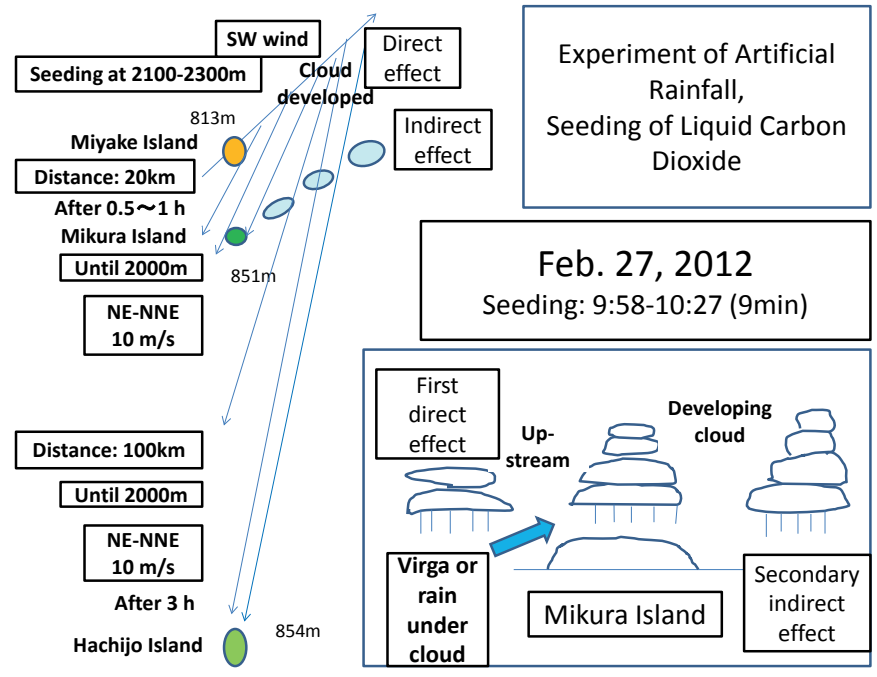

Fig. 6. Models of the wind direction and wind speed affected on artificial rainfall of LCD seeding around Miyake Island and of the effect to Mikura and Hachijo Islands.

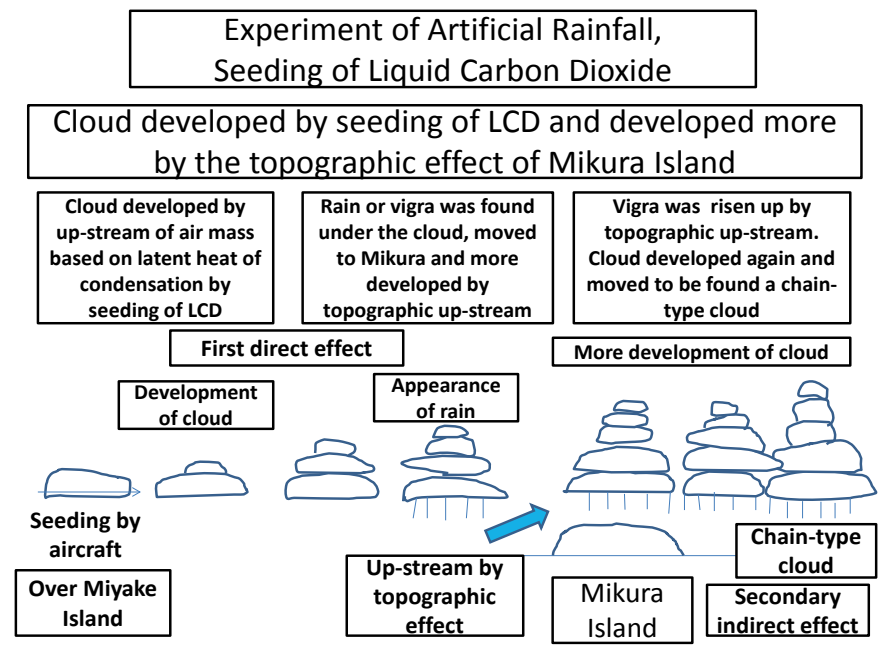

Fig. 7. Model of artificial rainfall by LCD seeding around Miyake Island and an action to Mikura Island.

The shape of Mikura Island is a sharp trapezoid, the area over $500 \mathrm{~m}$ is pretty wide and the island' $\mathrm{s}$ area is $20.55 \mathrm{~km}^{2}$. The highest point is Miyama Mountain at $851 \mathrm{~m}$ high. The bottom of the artificial cloud and virga that moved to Mikura was almost the same height as a peak of Mikura, and it could easily cover the island. Thus, the mountainous area of Mikura could be covered by rain. These phenomena agree with the appearance of topographic clouds and rain (Seto et al., 2011).
The radar image is shown in Fig. 8 and there is no image at 11:00 JST. The cloud developed as an ENE line- or chain-type typically after 11:10 JST and became high and thick by 11:30 JST to 12:10 JST in Fig. 8. The cloud could be seen by radar clearly, and the radar echoes reached 3000-5000 $\mathrm{m}$. The artificial cloud disappeared at 14:00 after $3 \mathrm{~h}$.

The possibility of artificial rainfall by LCD was very high and remarkable. The artificial cloud development is important, that is the cloud with the virga rose up at 


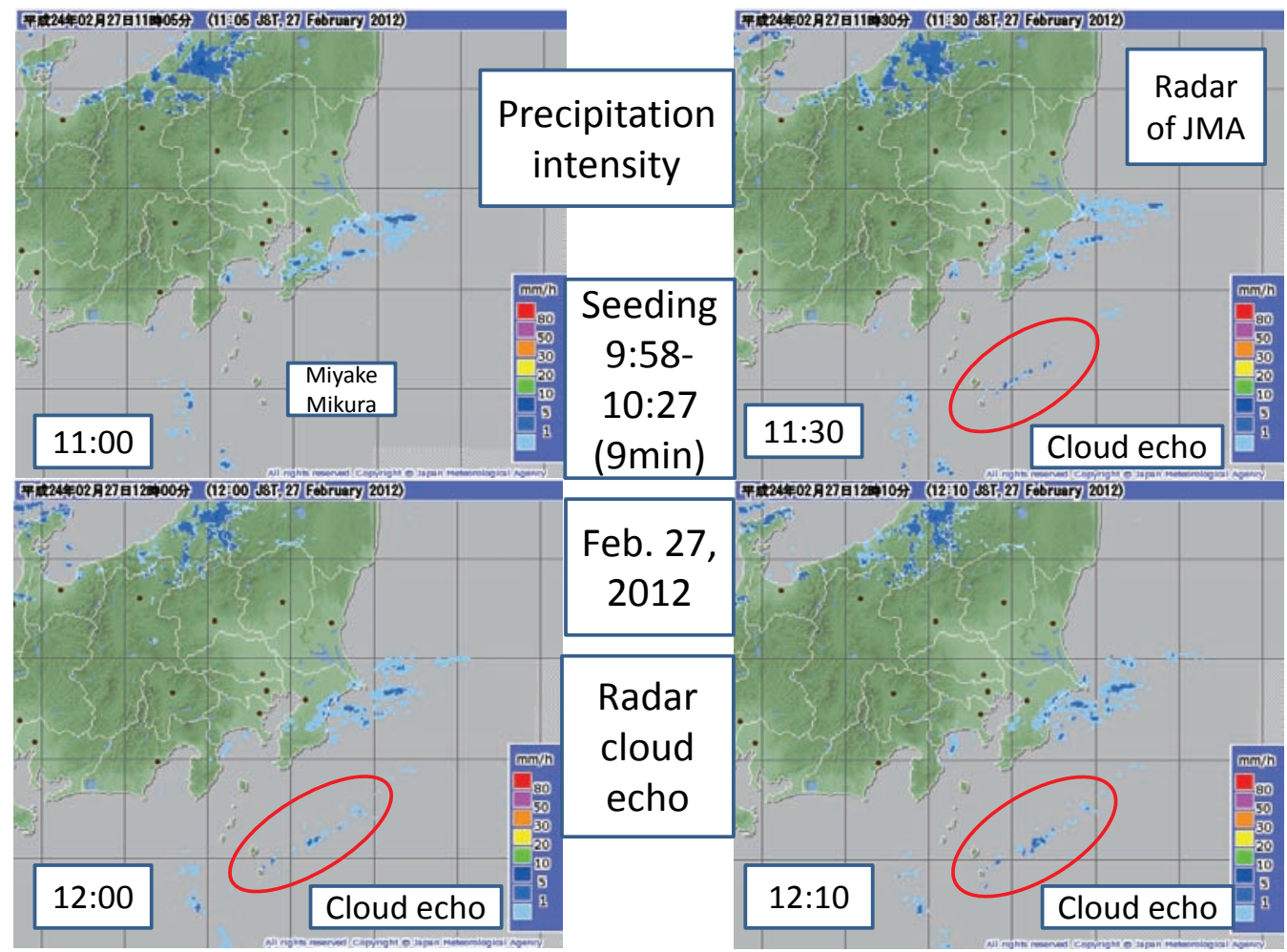

Fig. 8. Radar cloud echoes at 11:00 JST, 11:30 JST, 12:00 JST and 12:10 JST around Miyake, Mikura and Hachijo Islands (JMA).

the slope of the island, and the cloud developed further. The cloud was pushed by a SW wind around $2200 \mathrm{~m}$ and moved in an ENE direction. It eventually rose and appeared on the radar image as a chain-type cloud (Fig. 8). Such a phenomenon of the clouds appeared in about $1 \mathrm{~h}$ and disappeared in about $3 \mathrm{~h}$ is a proper result as an artificial effect. If the seeding was not done artificially, these clouds would not be found at all, we presumed and concluded.

The amount of rain or water was estimated as 1 million tons by the direct effect of LCD seeding around the main area of $10 \mathrm{~km}$ wide and $100 \mathrm{~km}$ long with precipitation intensity about $2 \mathrm{~mm} / \mathrm{h}(0-5 \mathrm{~mm} / \mathrm{h})$. The efficiency of LCD for rain was predicted at 3 million tons per $1 \mathrm{~kg}$ LCD. So, it was presumed that roughly 100 times more rain would be produced compared to the older three methods of dry ice, AgI, and salt-water seeding.

According to the observed vertical profile by upper air observation at 9:00 JST at Hachijo, the data were $\mathrm{W}$ wind at $4.2 \mathrm{~m} / \mathrm{s}, 10.2^{\circ} \mathrm{C}$ near the surface; NNW-N, $3.0-5.0 \mathrm{~m} / \mathrm{s}, 4.2--1.5^{\circ} \mathrm{C}$ at $700-1500 \mathrm{~m}$; NW-W, 7-29 $\mathrm{m} / \mathrm{s},-3.7--13.2^{\circ} \mathrm{C}$ at $2000-4000 \mathrm{~m}$; and at the higher layer $\mathrm{W}$ by westerly wind.

According to the mesoscale forecast model (MSM) at 9:00 JST near Miyake (Fig. 9), the data were W, $4.2 \mathrm{~m} / \mathrm{s}, 10.2^{\circ} \mathrm{C}$ at the plane of $925 \mathrm{hPa}$; ESE, $3.0 \mathrm{~m} / \mathrm{s}$ at $850 \mathrm{hPa}$; and WSW, $10.0 \mathrm{~m} / \mathrm{s}$ at $700 \mathrm{hPa}$. As it is usually that the radar echo is moved with the wind direction at the plane of $700 \mathrm{hPa}$, the moving radar echo that appeared in the ENE area agreed with the wind direction at the plane of $700 \mathrm{hPa}$, confirming that the cloud's development was caused by the LCD seeding as concerning the chain-type cloud.

\subsubsection{Effect of the LCD seeding at Miyake for Hachijo on Feb. 27}

According to the surface data observed at Hachijo, the data were $\mathrm{W}$ wind at $3.9 \mathrm{~m} / \mathrm{s}, 9.5^{\circ} \mathrm{C}$ at $10: 00 \mathrm{JST}$ (before the seeding); $\mathrm{NE}, 6.3 \mathrm{~m} / \mathrm{s}, 9.0^{\circ} \mathrm{C}$ at 11:00 JST, $\mathrm{NE}, 10.3 \mathrm{~m} / \mathrm{s}, 8.3^{\circ} \mathrm{C}$ at 12:00 JST; NE, $10.0 \mathrm{~m} / \mathrm{s}$, $8.3^{\circ} \mathrm{C}$ at $13: 00 \mathrm{JST}$; and $\mathrm{NE}, 9.5 \mathrm{~m} / \mathrm{s}, 8.4^{\circ} \mathrm{C}$ at $14: 00$ JST, with 0.0-0.5 mm/h rain (Fig. 10) . On Feb. 27, the rain record at 9:40-22:00 JST described rain at a maximum rate of $2.0 \mathrm{~mm} / \mathrm{h}$. A band-type cloud covered 


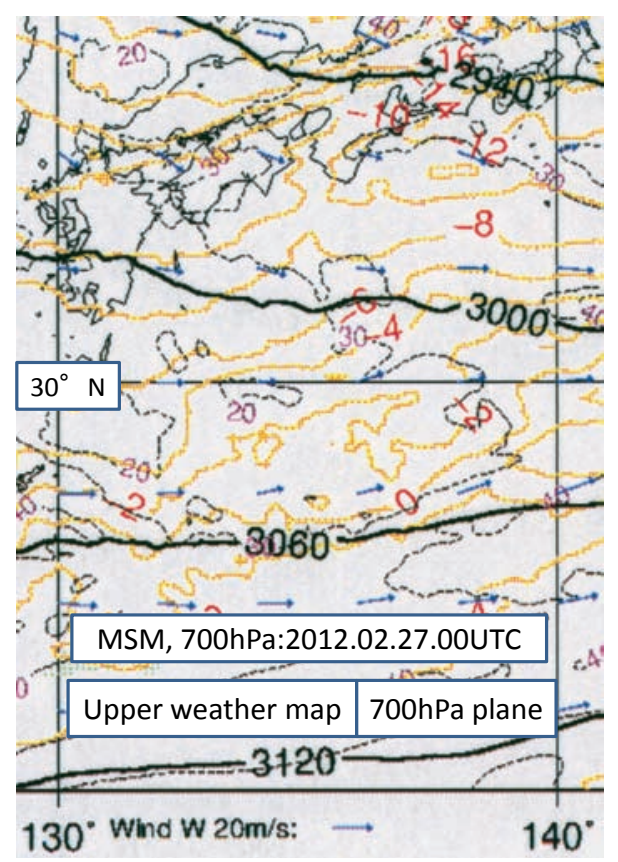

Fig. 9. Upper level weather map data of $700 \mathrm{hPa}$ (about $3000 \mathrm{~m}$ above the sea level) vertical height on Feb. 27, 2012 (JMA).

Hachijo at 9:00-9:50 JST, but the wind direction changed from $\mathrm{W}$ to NNE-NE suddenly at 10:40-10:50 JST and the cloud was destroyed. However, the change of weather at 11:00 JST shown in Figure 10 was at least $1 \mathrm{~h}$ earlier than the effect of the LCD seeding based on the wind speed at Hachijo. So, the sudden change of wind direction and wind speed was not a direct effect of the LCD seeding, but the possibility of wave transportation will be investigated.

The distance between Miyake and Mikura is $20 \mathrm{~km}$, and that between Miyake and Hachijo is $100 \mathrm{~km}$. As the artificial rain air mass or virga is mainly at a low layer, it will be moved by the wind at $10.2-17.3 \mathrm{~m} / \mathrm{s}$ $(50 \mathrm{~km} / \mathrm{h})$ at $0-2000 \mathrm{~m}$. Then, the cloud and virga was moved in the SW-SSW direction by a low-layer wind at $0.5-1 \mathrm{~h}$ after the seeding. Although the artificial cloud initially flew to the east side of Miyake, It was a possibility that the artificial air mass or virga arrived by northern winds at Hachijo, and the rain affected Hachijo about $3 \mathrm{~h}$ later. It was possible that the artificial rain and an increase in rain could be observed after 13:00 JST, but it was not always a perfect result of an artificial effect, and the process underlying these phenomena should be further investigated.
There are useful phenomena concerning the rain of islands on the subtropical and temperate rain forests.

1) A cloud forest does not cover on Chichi Island (peak, $318 \mathrm{~m}$ ) as one of the Ogasawara Islands about $1000 \mathrm{~km}$ directly south of Tokyo, but covers on a higher part of Haha Island $(463 \mathrm{~m})$ in another of Ogasawara. The rainfalls in these islands are based mainly on the height of the mountain areas.

2) The largest grove of pasania trees in Japan is on Mikura, fostering a rain forest climate. The annual amount of rain is $2953.6 \mathrm{~mm}$ in Miyake (813 m) and $3202.4 \mathrm{~mm}$ in Hachijo $(854 \mathrm{~m}$ ), and the peak of Mikura $(851 \mathrm{~m})$ is a similar height located in a similar climate. As the trapezoid shape of Mikura differs from those of the other islands, and many huge trees grow on it, it is presumed to have a similar or higher amount of rain. Unfortunately, there are no official data (JMA) about the rainfall on Mikura.

\subsection{Comparison of Feb. 26 and Feb. 27 experiments}

The seeded cloud was moved to the easterly side of Miyake by a W wind on Feb. 26 and by a WSW wind on Feb. 27, and these clouds developed significantly during the moving time. The artificial convective cloud was significant after 0.5 to $1 \mathrm{~h}$ of the LCD seeding and reached to $3000 \mathrm{~m}$ and $4000 \mathrm{~m}$ on Feb. 26 and 27, respectively. Then, the virga, i.e., air mass with rain under the cloud, was moved to Mikura about $1 \mathrm{~h}$ after the seeding by the wind at $0-2000 \mathrm{~m}$. Artificial clouds were presumed to have been observed on both days, and virga under the cloud and rain were observed on Feb. 27 by eye. The radar echo of higher artificial clouds was not detected on Feb. 26, but was detected clearly by radar on Feb. 27. This difference is based on the varying air temperature, vapor profiles, and wind direction. It is of note that an upper layer cloud appeared at the ENE side of Mikura on Feb. 27. The chain-type radar echoes observed at the ENE side of Mikura were clearly from an artificial cloud after 12:00 JST at 3000-5000 m (Fig. 8) .

The authors could not use another instruments and not detect in the aircraft due to a lack of funds, e.g., instruments to gauge cloud water content. We would like to get the radar data with RHI (range height indicator) and PPI (plan position indicator), but could not get it at these areas even if we have the radar of Kyushu University. We will set the portable radar at Mikura Island to detect during the next time if it is possible. Anyway, the artificial rainfall experiments succeeded. 


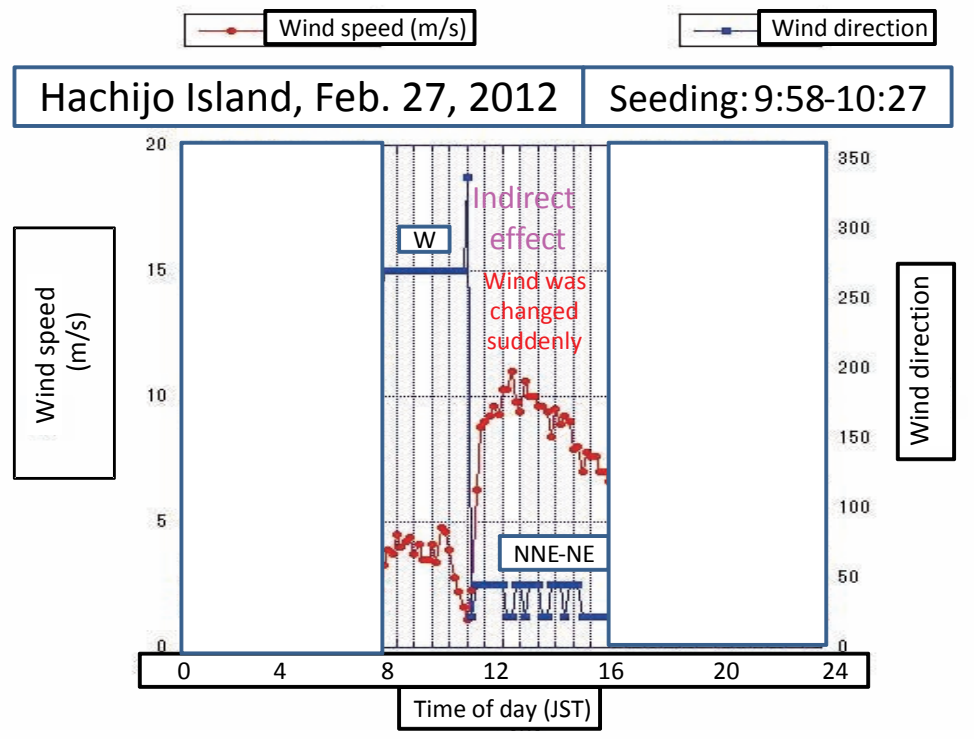

Fig. 10. Wind direction and wind speed at Hachijo Island on Feb. 27, 2012.

(1) At Miyake, no artificial clouds were produced on Feb. 26, but an artificial cloud was produced on Feb. 27.

(2) At Mikura, artificial clouds were observed by eye based on the wind direction and wind speed on both days, and virga and rain were observed on Feb. 27.

(3) At Hachijo, there was a possibility of rain and of an increase in rain; however there was no evidence of artificial rainfall in spite of the necessity for further investigation.

Comparing this data to other data observed at Northern Kyushu (Fukuta et al., 2000; Wakimizu et al., 2002; Maki et al., 2011; 2012; Suzuki, 2012), it was also found that light LCD seeding inside the bottom of a convective cloud is suitable when the air temperature is below $-5^{\circ} \mathrm{C}$ and the LCD seeding rate is about $5 \mathrm{~g} / \mathrm{s}$. Useful results were obtained from the artificial rainfall at the Izu Islands, such as separated islands not affected each other. The operation of artificial rainfall on the LCD seeding is supported by the results of the present study. The authors believe that an extension will be promoted here after.

\section{Conclusions}

The results of the artificial rainfall by aircraft seeding of liquid carbon dioxide (LCD) experiment, which was carried out from Feb. 26 to 27, 2012 near Miyake
Island of the Izu Islands, Tokyo, were as follows:

(1) The development of artificial convective clouds was significant after 0.5 to $1 \mathrm{~h}$ of the seeding at the easterly leeward side of Miyake Island and reached to the heights of $3000 \mathrm{~m}$ and $4000 \mathrm{~m}$ on Feb. 26 and 27, 2012, respectively. It was successful that the development of clouds was done artificially by the artificial seeding of LCD.

(2) There was an artificial cloud found on Miyake Island and rain was possible on the mountain on Feb. 27.

(3) The artificial clouds appeared after 0.5 to $1 \mathrm{~h}$ of seeding on two days at Mikura Island. It was presumed that the amount of rain increased on the mountainous area. The artificial cloud echoes were recognized on the composition radar echo on Feb. 27 by the relationship between the movements of upper and lower clouds by the wind. It was observed that the height of the chain-type cloud echo reached $3000 \mathrm{~m}$ to $5000 \mathrm{~m}$, when the artificial cloud moved to the ENE leeward side of Mikura Island.

(4) It was clearly successful that the artificial rain experiment was done on both days by the evaluation of rainfall at Miyake and Mikura Islands.

(5) It was recognized that seeding of liquid carbon dioxide is suitable at a little inside of the bottom of a convective cloud with an air temperature be- 
low $-5^{\circ} \mathrm{C}$ and an LCD seeding rate of about $5 \mathrm{~g} / \mathrm{s}$.

The authors believe that the practicality of the artificial rain technique of LCD seeding will be promoted.

\section{References}

Fukuta, N., 1988a. Meteorological Engineering-new method of meteorological control-, Meteorol. Res. Note, 213pp.

Fukuta, N., 1988b. The maximum rate of homogeneous ice nucleant in air by cooling. Proc. $12^{\text {th }}$ Intl. Conf. on Nucleation and Atoms Aerosols, Springer-Verlag, Vienna, 504-507.

Fukuta, N., Wakimizu, K., Nishiyama, K. Suzuki, Y. and Yoshikoshi, H., 2000. Large unique radar echoes in a new, self-enhancing cloud seeding, Atmos. Res., 55, 271-273.

Maki, T., Hashimoto, Y., Okushima, L., Mitsuno, T., Noguchi, N., Aoki, M., Isoda, H., Omasa, K., Goto, E., Suzuki, Y., Takatsuji, M., Nonami, H., Hashiguchi, K., Hayakawa, S., Murase, H., and Yamagata, T., 2008. External Report "Promotion of Artificial Rainfall Technique for Countermeasure of Drought and Prevention of Desertification". Science Council of Japan, Tokyo, 28pp (in Japanese).

Maki, T., Suzuki, Y., Wakimizu, K., Tomine, K., and Nishiyama, K., 2011. Artificial Rainfall, In Encyclopedia of Wind (ed. by Maki, T., Niino, H., Nomura, T., Hayashi, Y. and Yamakawa, S.), Maruzen Shuppan, Tokyo, 134-135 (in Japanese).

Maki, T., Suzuki, Y., Wakimizu, K. and Nishiyama, K., 2012. Aritificial Rainfall-from countermeasure of drought to water resources-, Gihodo Shuppan, Tokyo, 176pp (in Japanese).
Nagata, M., Wakimizu, K., Nishiyama, K., Fukuta, N., and Maki, T., 2005. Numerical simulation for optimal seeding operation using liquid carbon. J. Agric. Meteorol., 60 (5), 901-904.

Nishiyama, K., Fukuta, N. and Wakimizu, K., 2005. Theoretical approach for optimum seeding operation using carbon dioxide seeding. J. Agric. Meteorol., 60 (5), 721-724.

Ota, Y., Wakimizu, K., Nishiyama, K., Fukuta, N., and Maki, T., 2005. LC seeding test in western Kansas hail suppression possible hail fallout by air flux choking. J. Agric. Meteorol., 60 (5), 905-908.

Seto, J., Tomine, K., Wakimizu, K., and Nishiyama, K., 2011. Artificial cloud seeding using liquid carbon dioxide: Comparisons of experimental data and numerical analyses. J. Appl. Meteorol. Climatol., 50, 1417-1431.

Suzuki, Y., 2012. Document of artificial rainfall: succeeded example, Feb. 2, 1999, Aritificial Rainfallfrom countermeasure of drought to water resources (ed. by Maki, T., Suzuki, Y., Wakimizu, K. and Nishiyama, K.), Gihodo Shuppan, Tokyo, 92-95 (in Japanese).

Wakimizu, K., Nishiyama, K., Suzuki, Y., Tomine, K., Yamazaki, M., Ishimaru, A., Ozaki, M., Itano, T., Naito, G. and Fukuta, N., 2002. Low level penetration seeding experiment of liquid carbon dioxide in a convective cloud. Hydrol. Process, 16, 2239-2253. 